\title{
Wishes and Beliefs of Cancer Patients Regarding Counseling on Integrative Medicine
}

\author{
Karsten Münstedt ${ }^{\mathrm{a}}$ Tobias Vogt ${ }^{\mathrm{a}}$ Maria-Elisabeth Rabanus ${ }^{\mathrm{b}} \quad$ Jutta Hübner $^{\mathrm{c}}$ \\ a Department of Obstetrics and Gynecology, Justus-Liebig-University of Giessen, Germany

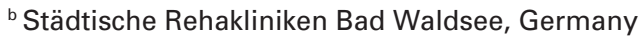 \\ ${ }^{\circ}$ German Cancer Society, Berlin, Gemany
}

Keywords

Complementary medicine $\cdot$ Alternative medicine . Counseling · Cancer

\section{Summary}

Background: Today there is an agreement on how patients should be counseled regarding integrative medicine in oncology. In order to better meet the patients' demands, we investigated additional beliefs and wishes related to these topics. Patients and Methods: Patients in 2 locations were asked to complete an assessment form regarding their wishes in relation to counseling on integrative medicine. Results: Based on 404 returned assessment forms, we found that most patients wished to be counseled on integrative medicine by oncologists but also wanted to be treated by them with such methods. Oncologists received the best ratings regarding credibility, oncological competence, sympathy for patients, and honesty. Only with regard to time for patients did health practitioners receive better ratings. Physical exercise, balanced diets, and psycho-oncological support were the methods mainly recommended by physicians. Health practitioners mainly recommended taking mistletoe extracts, trace elements, and immunostimulants. Conclusion: It may be hypothesized from this work that the physicians' leading role in promoting integrative medicine in the field of oncology - which contrasts with findings in other countries - is perhaps based on the patients' desire to be treated and counseled by physicians, especially oncologists.

\section{Introduction}

Integrative medicine is of high importance to cancer patients. In Europe, about $40 \%$ of all cancer patients use integrative medicine during or after cancer therapy [1,2]. Among others, lack of time and dissatisfaction with communication and the decision process in conventional medicine have been identified as important factors for why complementary and alternative medicine (CAM) or integrative medicine is used $[3,4]$.

Interestingly, there is an agreement on how patients should be counseled. Schofield et al. [5] issued 10 evidence-based recommendations. These demand (1) to elicit the person's understanding of their situation, (2) to respect cultural and linguistic diversity and different epistemological frameworks, (3) to ask questions about integrative medicine use at critical points in the illness trajectory, (4) to explore details and actively listen, (5) to respond to the person's emotional state, (6) to discuss relevant concerns while respecting the person's beliefs, (7) to provide balanced, evidence-based advice, (8) to summarize discussions, (9) to document the discussion, and (10) to monitor and follow up. Schofield et al. [5] believe that it is important to encourage informed decision-making about integrative medicine and thus hopefully improve the patients' outcomes. The working group 'Prevention and Integrative Oncology' of the German Cancer Society has worked out how these recommendations can be put into practice [6]. In order to be able to better meet the patients' demands in the future, we initiated this project to integrate their beliefs and wishes in relation to integrative medicine into counseling.

\section{KARGER \\ Fax +497614520714}

Information@Karger.com

www.karger.com (c) 2014 S. Karger GmbH, Freiburg

$1661-3791 / 14 / 0096-0416 \$ 39.50 / 0$

Accessible online at:

www.karger.com/brc 


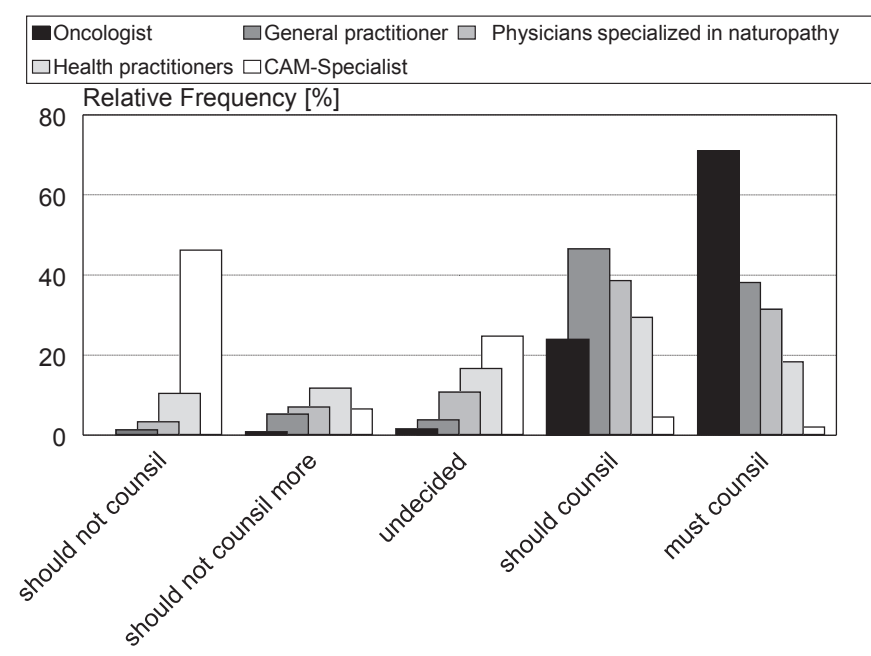

Fig. 1. Patients' answers to the question on who should counsel on CAM.

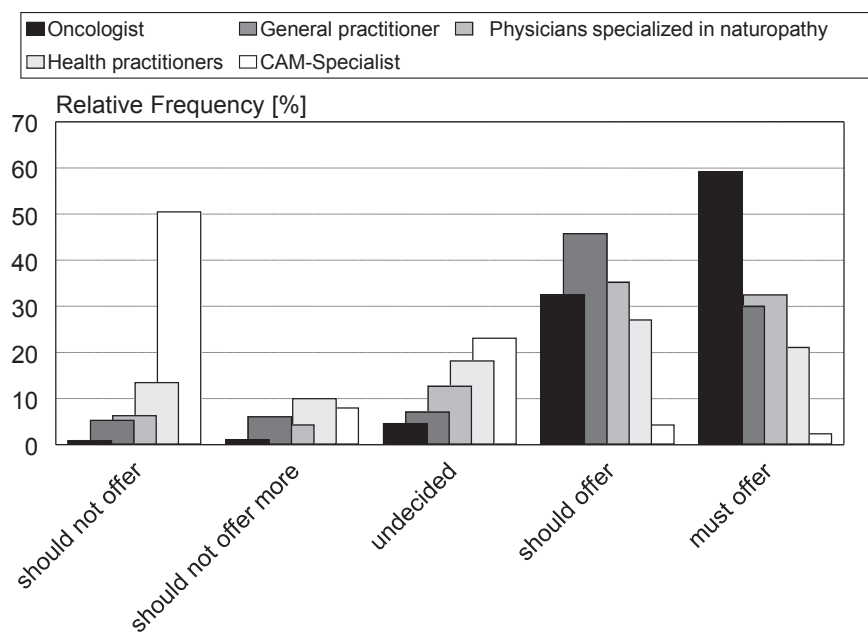

Fig. 2. Patients' answers to the question on who should offer CAM.

\section{Patients and Methods}

Patients were asked to complete an assessment form on the topic; the form was newly developed based on the questions addressed here. The assessment form was tested on 10 volunteers for intelligibility (annotation: this was not a psychological questionnaire, which would have required validation). Apart from that, patients had the chance to ask the people involved in this study (M.-E.R., T.V.) about issues that remained unclear to them. Criteria for inclusion in the study were the ability to read and write in German, a life expectancy of more than 3 months, and a Karnofsky index of 90 or better. A copy of the assessment form can be obtained from the first author.

Prior to the start of this study, the study plans were presented to the local ethics committee, which gave its consent on March 22, 2011 (registration number 64/11).

Clinical data and data from the assessment forms were recorded using SPSS for Windows, which was also used for descriptive and analytical statistics (paired t-test). After assessment, all data were anonymized.

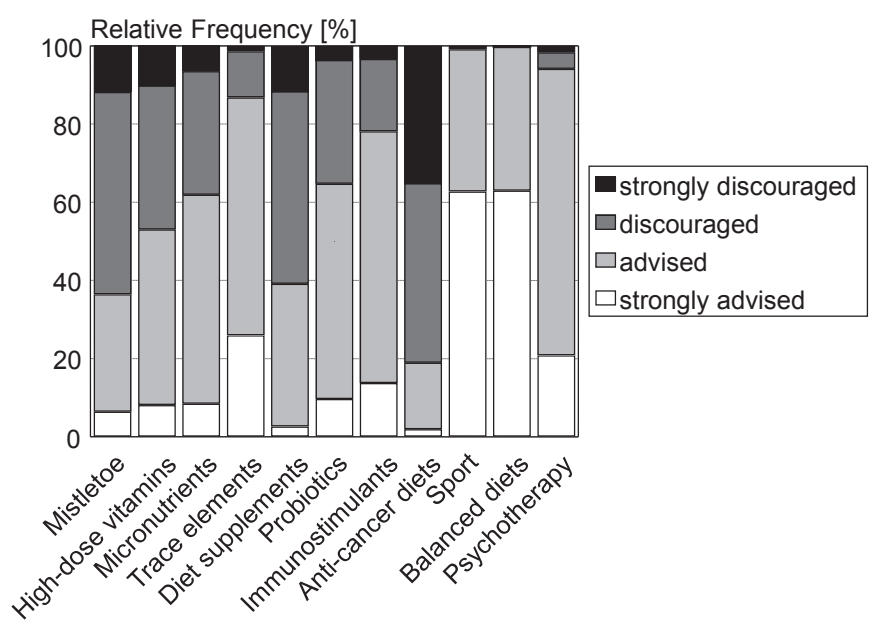

Fig. 3. Advice on various CAM methods.

\section{Results}

Between March 2012 and August 2012 we contacted all consecutive patients seen by T.V. in the oncological outpatient department of the clinic for obstetrics and gynecology at the University of Giessen, Germany. Parallel to that, 500 consecutive breast cancer patients were contacted in a rehabilitation hospital in Bad Waldsee between April 2012 and December 2012. In all, we distributed 700 questionnaires. Altogether 423 questionnaires were received back. However, 19 questionnaires were incomplete. Thus, this left 404 questionnaires for evaluation. The characteristics of these patients are summarized in table 1.

When we asked the patients about who should counsel them on integrative medicine, clearly most of the patients wished to be counseled by physicians, especially by oncologists. The details of this question are depicted in figure 1. Similarly, patients also wanted to be treated with integrative medicine by physicians, especially oncologists (fig. 2).

In the second part of our questionnaire, we addressed the patients' ratings of the professionalism of providers from different professions. Oncologists received the best ratings regarding credibility, oncological competence, sympathy for patients, and honesty. Only with regard to time for patients did health practitioners receive better ratings (table 2). All differences between the ratings regarding the different professional groups are statistically significant $\left(\mathrm{p}_{\mathrm{t}-\mathrm{test} \text { for paired samples }}<0.001\right)$.

Among various recommendations, sports and balanced diets were recommended the most; anticancer diets, mistletoe, and diet supplements were discouraged the most (fig. 3). Asked about the efficiency of different methods of integrative medicine, the patients considered physical activity, balanced diets, and psycho-oncological support as the most effective. Anticancer diets, diet supplements, and high-dose vitamins were regarded as least effective. The patients were indecisive regarding the efficacy of most methods. As a result, sports, 
Table 1. Patient characteristics

\begin{tabular}{|c|c|c|c|}
\hline Variable & Entire collective $(n=404)$ & Bad Waldsee $(n=275)$ & Giessen $(n=129)$ \\
\hline Age, years, mean (SD) & $58.0(11.1)$ & $57.3(10.7)$ & $59.4(1.8)$ \\
\hline Weight, kg, mean (SD) & $71.3(15.3)$ & $71.4(15.4)$ & $71.1(16.3)$ \\
\hline Height, cm, mean (SD) & $164(10)$ & $163(12)$ & $165(6)$ \\
\hline \multicolumn{4}{|l|}{ Place of living, n (\%) } \\
\hline Country & $230(56.9)$ & $146(53.1)$ & $84(65.1)$ \\
\hline City & $167(41.3)$ & $123(44.7)$ & $44(34.1)$ \\
\hline Missing & $7(1.7)$ & $6(2.2)$ & $1(0.8)$ \\
\hline \multicolumn{4}{|l|}{ Family status, n (\%) } \\
\hline Married & $256(63.4)$ & $177(64.4)$ & $79(61.2)$ \\
\hline Widowed & $52(12.9)$ & $31(11.3)$ & $21(16.3)$ \\
\hline Single & $37(9.2)$ & $29(10.5)$ & $8(6.2)$ \\
\hline Divorced & $53(13.1)$ & $32(11.6)$ & $21(16.3)$ \\
\hline Missing & $6(1.5)$ & $6(2.2)$ & $0(0.0)$ \\
\hline Number of children, $n$, mean (SD) & $1.7(1.1)$ & $1.7(1.1)$ & $1.8(1.1)$ \\
\hline \multicolumn{4}{|l|}{ Education, $\mathrm{n}(\%)$} \\
\hline None & $4(1.0)$ & $2(0.7)$ & $2(1.6)$ \\
\hline Secondary school & $134(33.2)$ & $85(30.9)$ & $49(38.0)$ \\
\hline Junior high school & $165(40.8)$ & $122(44.4)$ & $43(33.3)$ \\
\hline University entrance/diploma & $96(23.8)$ & $64(22.9)$ & $32(24.8)$ \\
\hline Missing & $5(1.2)$ & $2(0.7)$ & $3(2.3)$ \\
\hline \multicolumn{4}{|l|}{ Occupation, n (\%) } \\
\hline Unemployed & $9(2.2)$ & $6(2.2)$ & $38(29.5)$ \\
\hline Housewife & $36(8.9)$ & $20(7.3)$ & $3(2.3)$ \\
\hline Retired & $161(39.9)$ & $92(33.5)$ & $16(12.4)$ \\
\hline Working & $193(47.8)$ & $155(56.4)$ & $69(53.5)$ \\
\hline Missing & $5(1.2)$ & $2(0.7)$ & $3(2.3)$ \\
\hline \multicolumn{4}{|l|}{ Occupational category, n (\%) } \\
\hline Unskilled worker & $21(5.2)$ & $11(4.0)$ & $10(7.8)$ \\
\hline Skilled worker & $29(7.2)$ & $12(4.4)$ & $17(13.2)$ \\
\hline Employee & $149(36.9)$ & $101(36.7)$ & $48(37.2)$ \\
\hline Executive employee & $51(12.6)$ & $42(15.3)$ & $9(7.0)$ \\
\hline Government employee (middle grade of the civil service) & $8(2.0)$ & $4(1.5)$ & $4(3.1)$ \\
\hline Government employee (higher grade of the civil service) & $5(1.2)$ & $3(1.1)$ & $2(1.6)$ \\
\hline Self-employed & $38(9.4)$ & $26(9.4)$ & $12(9.3)$ \\
\hline Missing & $103(25.4)$ & $76(27.6)$ & $27(21.0)$ \\
\hline \multicolumn{4}{|l|}{ Tumor entity, n (\%) } \\
\hline Breast & $350(86.6)$ & $275(100.0)$ & $75(58.1)$ \\
\hline Ovary & $24(5.9)$ & - & $24(18.6)$ \\
\hline Cervix uteri & $9(5.9)$ & - & $9(7.0)$ \\
\hline Endometrial & $6(1.5)$ & - & $6(4.7)$ \\
\hline Vulva & $5(1.2)$ & - & $5(3.9)$ \\
\hline Fallopian tube & $2(0.5)$ & - & $2(1.6)$ \\
\hline Multiple & $1(0.2)$ & - & $7(5.4)$ \\
\hline Missing & $350(86.6)$ & - & $1(0.8)$ \\
\hline \multicolumn{4}{|l|}{ Time of diagnosis, $\mathrm{n}(\%)$} \\
\hline$<2000$ & $23(5.7)$ & $0(0.0)$ & $23(17.8)$ \\
\hline 2001-2005 & $20(5.0)$ & $3(1.1)$ & $17(13.2)$ \\
\hline 2006-2010 & $130(32.2)$ & $69(25.1)$ & $61(47.3)$ \\
\hline$>2011$ & $228(56.4)$ & $201(73.1)$ & $27(20.9)$ \\
\hline Missing & $3(0.7)$ & $2(0.7)$ & $1(0.8)$ \\
\hline \multicolumn{4}{|l|}{ Metastatic disease, n (\%) } \\
\hline Yes & $45(11.1)$ & $15(5.5)$ & $31(24.0)$ \\
\hline No & $343(84.9)$ & $245(89.1)$ & $98(76.0)$ \\
\hline Missing & $15(3.9)$ & $15(5.5)$ & - \\
\hline
\end{tabular}

$\mathrm{SD}=$ Standard deviation . 
Table 2. Patients' judgments on people involved in oncological treatments ${ }^{\mathrm{a}}$

\begin{tabular}{lccccc}
\hline & Credibility & $\begin{array}{l}\text { Oncological } \\
\text { competence }\end{array}$ & $\begin{array}{l}\text { Sympathy for } \\
\text { patients }\end{array}$ & Time for patients & Honesty \\
\hline Oncologists & $1.6(0.8)$ & $1.4(0.6)$ & $1.9(1.0)$ & $2.3(1.2)$ & $1.7(0.8)$ \\
General practitioners & $1.9(0.9)$ & $2.9(1.1)$ & $2.0(0.9)$ & $2.3(1.2)$ & $1.9(0.9)$ \\
Physicians specialized in naturopathy & $2.3(1.0)$ & $3.1(1.1)$ & $2.2(0.8)$ & $2.2(0.9)$ & $2.3(1.0)$ \\
Health practitioners & $3.0(1.2)$ & $3.9(1.3)$ & $2.2(1.2)$ & $2.1(1.1)$ & $2.9(1.2)$ \\
Non-medical specialists for a certain & $5.3(1.1)$ & $5.5(0.8)$ & $4.2(1.9)$ & $3.6(2.1)$ & $5.1(1.4)$ \\
CAM treatment & & & & & \\
\hline
\end{tabular}

${ }^{a}$ Mean values and SD of ratings according to German school grades are given: $1=$ very good, $2=$ good, $3=$ satisfactory, $4=$ adequate, $5=$ faulty, $6=$ insufficient.

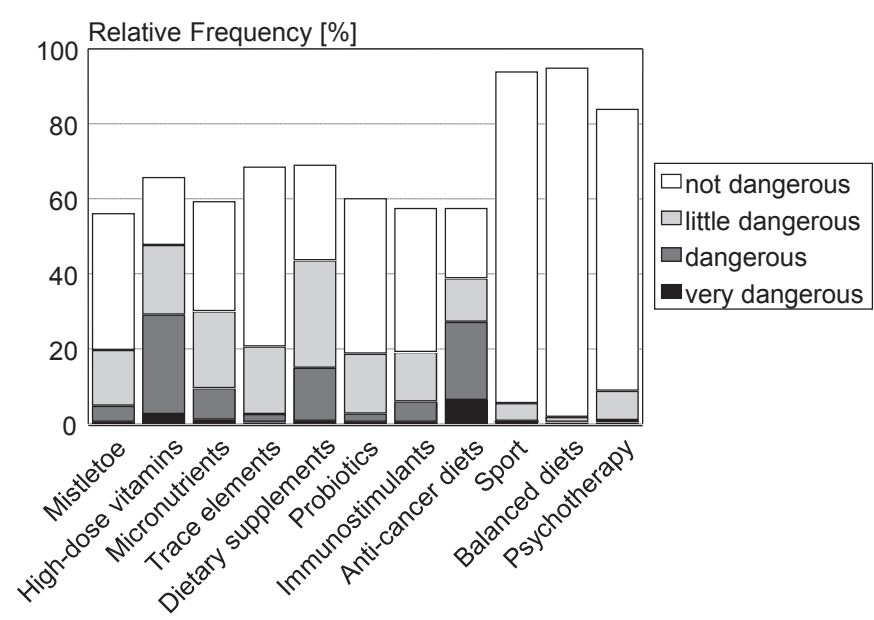

Fig. 4. Patients' perceptions of the risks of various methods.

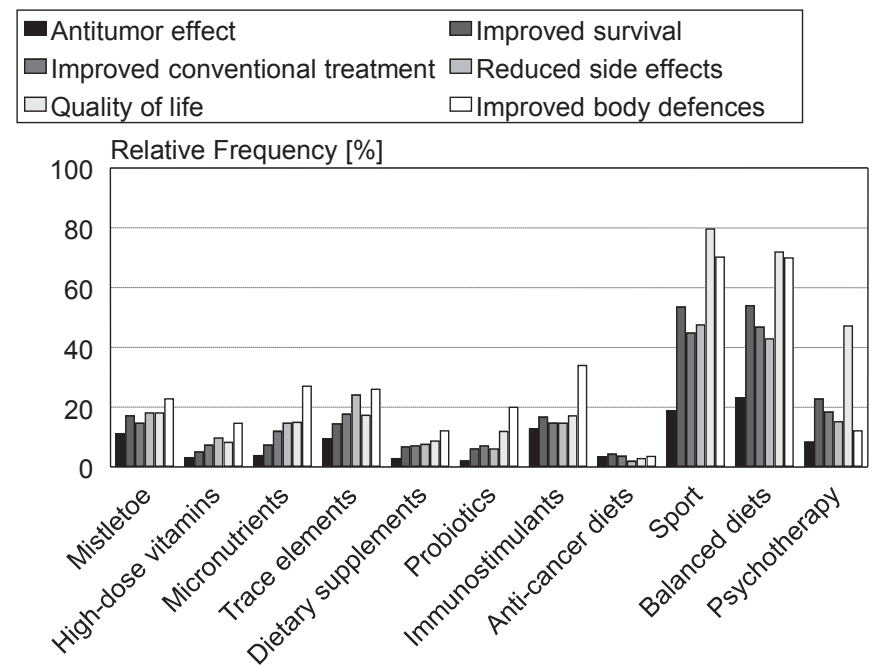

Fig. 5. Patients' perceptions of the treatment concepts of various methods.

balanced diets, and trace elements are the most frequently used methods and have high rates of past use and intended use. When considering risks, patients weighed high-dose vitamins and anticancer diets as most dangerous whereas physical activity and balanced diets were mostly regarded as not dangerous (fig. 4). High-dose vitamins were rated as dangerous or very dangerous by $29.1 \%$ of the patients.

Finally, the patients were asked about their expectations regarding different methods of integrative medicine. Drawing from earlier publications, we offered various goals relevant to therapy and life balance. Sports and balanced diets were regarded as most effective in achieving various aims of integrative cancer care (fig. 5).

\section{Discussion}

This survey shows that female German cancer patients want to be counseled directly by their oncologists and would also prefer oncologists to provide methods from integrative oncology. Most importantly, sports and balanced diets rate highly among cancer patients. Patients are strongly convinced that these methods exert multiple positive effects on the cancer disease and treatment.

Clearly, our results do not come from a representative study because we have only investigated patients who are under current treatment with conventional medicine and not those who have turned to alternative medicine or who refuse any treatment at all. We also did not assess the background of the patients' judgments, for example whether the judgment on health practitioners is based on personal experiences or not. There is a selection bias because we focused on patients in contact with conventional medicine and had no contact with patients who primarily turned to alternative medicine. However, within the referred group, the selection bias seems to be low, particularly because the hospital in Bad Waldsee is a referral center for postoperative rehabilitation of breast cancer patients in the Upper Swabia region in Germany.

The results of this study are well in line with data from Canada, which showed that patients prefer receiving information on integrative medicine from their oncologist [7]. According to a worldwide study of patient advocacy groups for chronic myelogenous leukemia, physicians seem to play a minor role regarding the promotion of integrative medicine, 
whereas in a former study, we have already shown that the situation is different in Germany [8-10]. In contrast to studies by Verhoef et al. [7] and Eng et al. [11], the data presented in this article confirm that, in Germany, oncologists together with general practitioners are an important source of information on integrative medicine. The question as to why Germany is different from many other parts of the world remains unanswered. There may be several explanations: One explanation may be that there are about 20,000 health practitioners and many other therapists from integrative medicine who also offer their services in the field of oncology, which makes physicians respond to this fact. Another explanation is that physicians have already adapted to the patients' demands and are willing to offer treatments from integrative medicine. Finally, it is possible that the acceptance of homoeopathy and anthroposophy by the German legislation allowed German physicians to specialize in these fields, which also prompted interest in other fields of integrative medicine. The fact that patients also consider effective those methods recommended to them by their physician underlines the great trust of patients in their oncologists. Similarly, patients rated the same methods as dangerous as are regarded as dangerous from the point of view of evidence-based medicine. The fact that physical activity and special attention to diet (but not cancer diets) have a high prevalence in cancer patients is supported by the results of a recent study from Switzerland [12]. The study by Templeton et al. [12] also shows that use of complementary methods has a much lower prevalence. Earlier studies in Germany have shown that vitamins and mistletoe extracts are the main treatments offered by integrative medicine [10,13]. The question remains open as to whether these differences exist due to the different collectives of patients or whether there is a real change in user behavior. The latter could be true as more and more oncologists realize the importance of giving guidance to their patients and turn to counseling them on integrative methods, which also seems to be the preferred choice of the patients. However, there is no formal education in this field in Germany and many physicians, including oncologists, are not sufficiently informed on integrative medicine. Thus, oncological integrative medicine experts should primarily provide oncologists with education based on evidence-based recommendations [14].

\section{Disclosure Statement}

None of the authors has a conflict of interest to disclose.

\section{References}

1 Molassiotis A, Fernandez-Ortega P, Pud D, Ozden G, Scott JA, Panteli V, Margulies A, Browall M, Magri M, Selvekerova S, Madsen E, Milovics L, Bruyns I, Gudmundsdottir G, Hummerston S, Ahmad AM, Platin N, Kearney N, Patiraki E: Use of complementary and alternative medicine in cancer patients: a European survey. Ann Oncol 2005; 16:655-663

2 Horneber M, Bueschel G, Dennert G, Less D, Ritter E, Zwahlen M: How many cancer patients use complementary and alternative medicine? A systematic review and meta-analysis. Integr Cancer Ther 2012;11:187-203.

$\checkmark 3$ Eschiti VS: Lesson from comparison of CAM use by women with female-specific cancers to others: it's time to focus on interaction risks with CAM therapies. Integr Cancer Ther 2007;6:313-344.

$\checkmark 4$ Hann D, Allen S, Ciambrone D, Shah A: Use of complementary therapies during chemotherapy: influence of patients' satisfaction with treatment decision making and the treating oncologist. Integr Cancer Ther 2006;5:224-231.

5 Schofield P, Diggens J, Charleson C, Mariglanie R, Jefford M: Effectively discussing complementary and alternative medicine in a conventional oncology setting: communication recommendations for clinicians. Patient Educ Couns 2010;79:143-151.
6 Hübner J, Muenstedt K, Muecke R, Micke O, Stoll C, Kleeberg UR, Buentzel J, Dennert G, Prott FJ; on behalf of PRIO (Working Group Prevention and Integrative Oncology of the German Cancer Society) and AKTE (Working Group Trace Elements of the German Society of Radiooncology (DEGRO): Counseling cancer patients on complementary and alternative medicine: background, theory, and implementation of nationwide counseling facilities. Strahlenther Onkol 2013;189:613617.

7 Verhoef MJ, Trojan L, Armitage GD, Carlson L, Hilsden RJ: Complementary therapies for cancer patients: assessing information use and needs. Chronic Dis Can 2009;29:80-88.

-8 Elsner T, Muecke R, Micke O, Prott FJ, Muenstedt K, Waldmann A, Geissler J, Huebner J: Survey on the worldwide Chronic Myeloid Leukemia Advocates Network regarding complementary and alternative medicine. J Cancer Res Clin Oncol 2013;139: $1025-1031$.

9 Münstedt K, Kirsch K, Milch W, Sachsse S, Vahrson $\mathrm{H}$ : Unconventional cancer therapy - survey of patients with gynaecological malignancy. Arch Gynecol Obstet 1996;258:81-88.
10 Nagel G, Hoyer H, Katenkamp D: Use of complementary and alternative medicine by patients with breast cancer: observations from a health-care survey. Support Care Cancer 2004;12:789-796.

11 Eng J, Ramsum D, Verhoef M, Guns E, Davison J, Gallagher R: A population-based survey of complementary and alternative medicine use in men recently diagnosed with prostate cancer. Integr Cancer Ther 2003;2:212-216.

12 Templeton AJ, Thürlimann B, Baumann M, Mark M, Stoll S, Schwizer M, Dietrich D, Ruhstaller T: Cross-sectional study of self-reported physical activity, eating habits and use of complementary medicine in breast cancer survivors. BMC Cancer 2013;13:153.

13 Micke O, Bruns F, Glatzel M, Schönekaes K, Micke P, Mücke R, Büntzel J: Predictive factors for the use of complementary and alternative medicine (CAM) in radiation oncology. Eur J Integr Med 2009;1:22-30.

14 Trimborn A, Senf B, Muenstedt K, Buentzel J, Micke O, Muecke R, Prott FJ, Wicker S, Huebner $\mathrm{J}$; on behalf of PRIO (Working Group Prevention and Integrative Oncology of the German Cancer Society): Attitude of employees of a university clinic to complementary and alternative medicine in oncology. Ann Oncol 2013;24:2641-2645. 